\title{
MÁS SOBRE EL MOTIVO DE "LA MISTERIOSA AMA DE CASA" EN LA TRADICIÓN ORAL INDOAMERICANA
}

\author{
Enrique Margery Peña
}

\begin{abstract}
RESUMEN
Se hace necesario proponer una distribución geografía diferente de los componentes del motivo de "la misteriosa ama de casa" presentados en un artículo reciente del autor. Esta clasificación se basa en un texto de Kaliña, un grupo caribeño, y por referencias hechas en la versión arahuaca. Además, en el artículo se incluyen observaciones con respecto a algunos elementos de este motivo en un texto nivaklé.
\end{abstract}

\begin{abstract}
A text by Kaliña -a Caribbean people- and the reference of an Arahuacan version make it necessary to restate the geographical distribution of the components of the motif of "Mysterious housekeeper" ( $\mathrm{N}$ 831.1) that the author presented in a recent article. Furthermore, this paper includes observations regarding some elements of this motif in a nivaklé text.
\end{abstract}

\section{Preliminares}

En un reciente artículo (Margery Peña 1995) destinado a la descripción de los componentes narrativos del motivo de "la misteriosa ama de casa"(N 831.1) 1 en la tradición oral indoamericana, exponíamos acudiendo a su mostración en mapas -de los cuales aquí se reproducen sólo las zonas pertinentes- las respectivas procedencias, así como la distribución geográfica de tres de tales componentes. Los mapas correspondientes son los que a continuación se incluyen. 
Mapa 1

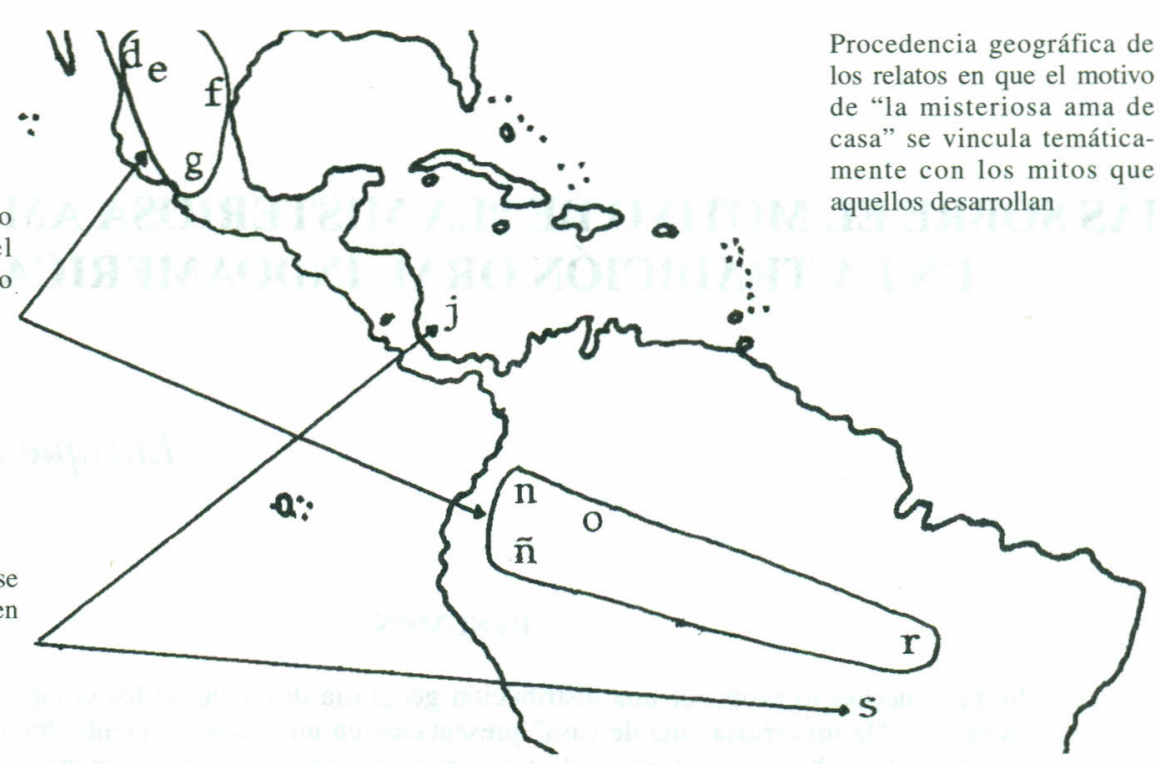

Relatos en los que el motivo se vincula con el mito del origen de un clan.

Relatos en los que el motivo se vincula con el mito del repoblamiento del mundo después de un cataclismo.

(En éste, como en los mapas subsiguientes, las letras minúsculas corresponden a versiones de las procedencias que a continuación se detallan: a esquimal del Este de Groenlandia; b esquimal del Labrador; c cree; $\mathbf{d}$ huichol; e tepecano; $\mathbf{f}$ totonaco; $\mathbf{g}$ tlapaneco; $\mathbf{h}$ popoluca; $\mathbf{i}$ caribeño; $\mathbf{j}$ bribri; $\mathbf{k}$ cabécar; $\mathbf{I}$ cuna; $\mathbf{m}$ arahuaco o caribe; $\mathbf{n}$ cañarí; $\tilde{\mathbf{n}}$ maina; $\mathbf{o}$ jívaro; $\mathbf{p}$ shikrin; $\mathbf{q}$ apinayé; $\mathbf{r}$ karajá; $\mathbf{s}$ bororo).

Mapa 2

Perro (a)
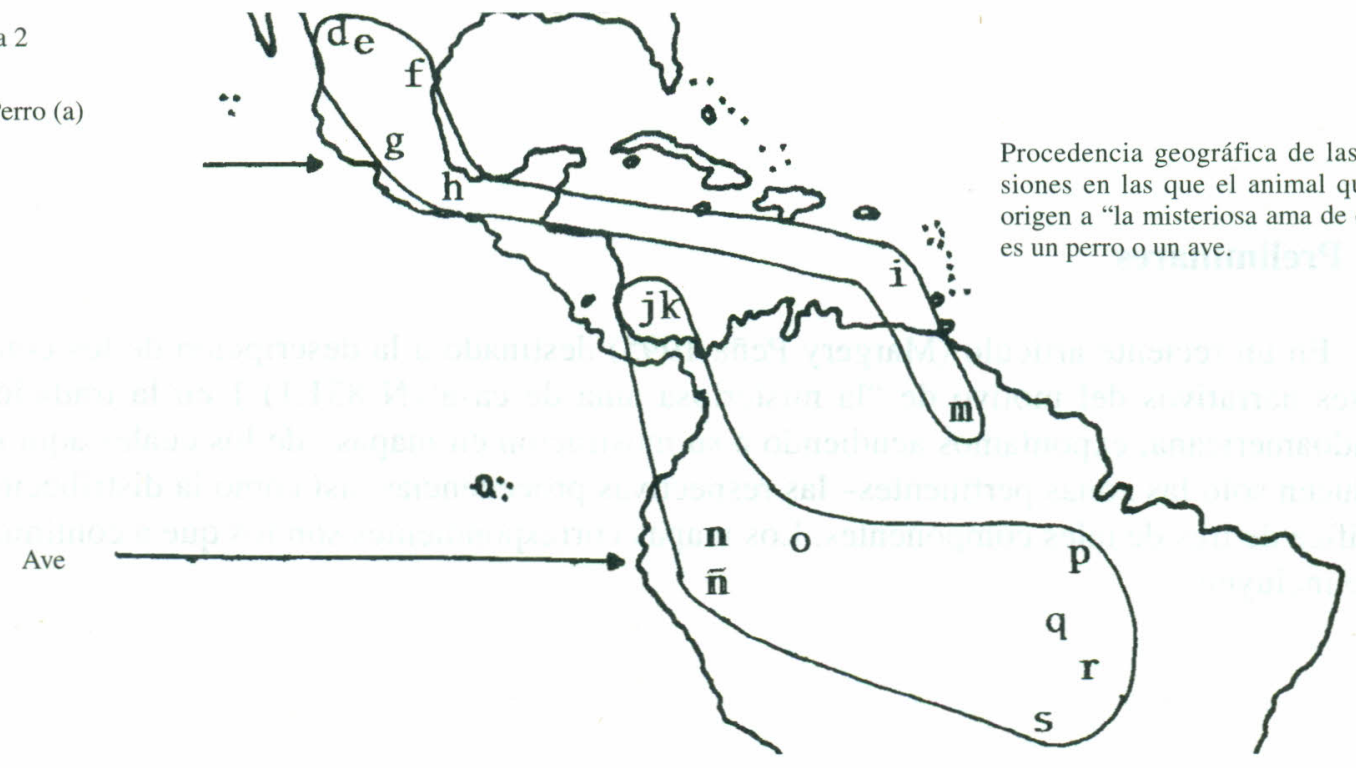
Mapa 3

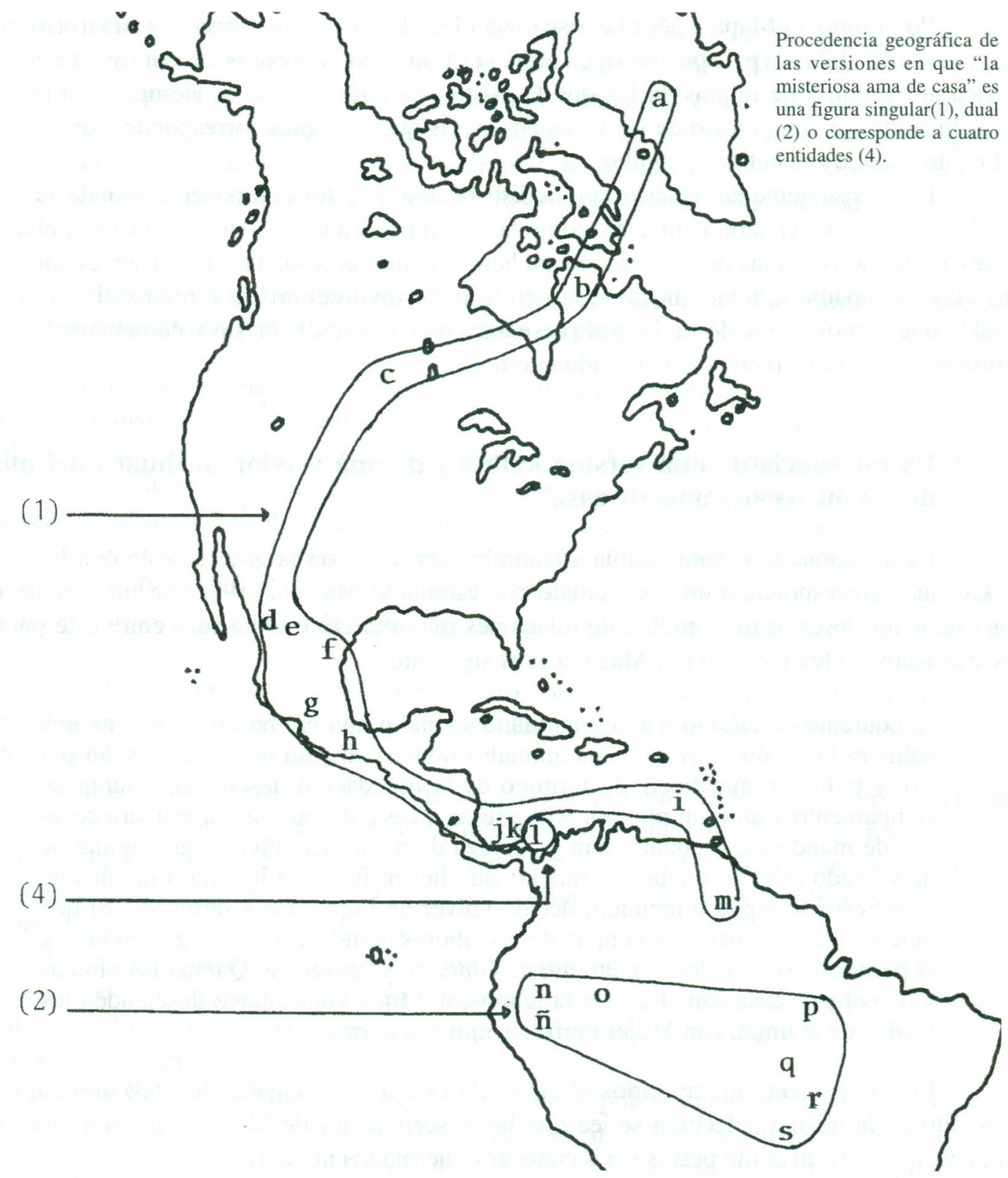

Entre los aspectos relevantes señalados en el artículo, y que a su vez se aprecian en estos mapas, cabe anotar en primer lugar que en las versiones mesoamericanas, así como en la cañarí (n),

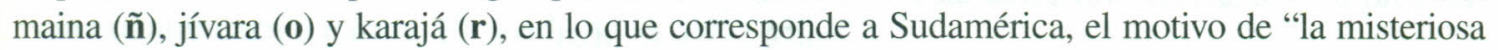
ama de casa" se vincula con el mito del repoblamiento del mundo después del diluvio, con excepción del texto karajá en el que el cataclismo lo constituye el gran incendio del mundo.

A su vez, en el Mapa 2 se aprecia que en las versiones bribri (j), cabécar (k), cañarí (n),

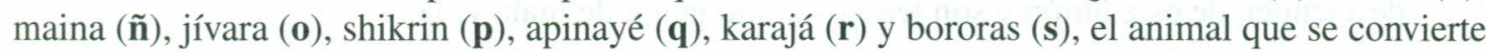
en la misteriosa ama de casa es siempre un ave, en contraste con las versiones mesoamericanas y caribeñas en las que tal entidad corresponde a un perro o a una perra. 
Por último, el Mapa 3 permite visualizar el hecho de que las versiones cañarí (n), maina $(\tilde{\mathbf{n}})$, jívara (o), shikrin (p), apinayé $(\mathbf{q})$, karajá (r) y los textos bororos (s) configuran en Sudamérica un conjunto de relatos en los que la misteriosa ama de casa es siempre una pareja de aves, en contraste con el resto de las versiones en las que tal figura corresponde, con excepción del relato cuna, a una entidad singular.

Es precisamente en relación con la distribución de estos componentes donde se aprecia la relevancia de una versión kaliña, así como las referencias a una versión arahuaca, ambas referentes a este motivo, a las que recientemente hemos tenido acceso. Tras los alcances sobre estas dos últimas versiones, hemos incorporado en la parte final del artículo, referencias a un texto nivaklé que hemos estimado de interés presentar como cierre de nuestros comentarios sobre la difusión de este motivo en el ámbito indoamericano.

\section{La relevancia de una versión kaliña y de una versión arahuaca del motivo de "la misteriosa ama de casa"}

La mencionada versión kaliña -denominación ésta con la que se designa a los caribes de Guyana- corresponde a un texto citado por Edmundo Magaña (1992) en un artículo en el que este autor describe un conjunto de relaciones inter-étnicas establecidas entre este pueblo y los arahuacos. El texto citado por Magaña es el siguiente:

(...) durante un diluvio o una gran inundación, un hombre buscó refugio en una palmera llevando consigo a sus animales domésticos, un guacamayo y un perro, y tallos de mandioca. Al término de la inundación desciende, levanta un campamento y abre un plantío. Al regresar a casa, después de la primera cosecha de mandioca, encuentra pan y cerveza de mandioca. Piensa que alguien le ha visitado pero no encuentra huellas que lleven fuera de la casa. Finalmente, como esto se repite a menudo, decide volver de improviso y descubre así que quienes hacen el pan y se ocupan de las labores domésticas son el guacamayo y el perro que se transforman en mujeres durante su ausencia. Quema las plumas y la piel y se casa con ellas. De la unión con Mujer Guacamayo descienden los kaliña, de la unión con Mujer Perro las mujeres arawak.

En sus comentarios referidos al cierre de este texto, Magaña (Id.; 63) anota que "En otro mito de la misma colección se lee que las descendientes de Mujer Perro son putas y, en otro aún, que "vivían como perros sin reconocer ni hermanos ni padres".

No obstante, de mayor importancia para los contenidos del presente artículo, resulta la observación del propio Magaña (Id.; 64) que citamos a continuación:

(...) en la mitología arawak misma se encuentra que algunos clanes arawak descienden de Mujer Perro. El mito narra la misma historia que los mitos kaliña sobre el origen de los arawak: (...) la gente del clan Perro o Ibeswanano descienden de esta unión y son tenidos como gente de mala vida. 
La versión kaliña y las referencias de Magaña sobre el mito arahuaco implican la necesidad de revisar la distribución geográfica de tres componentes de este motivo que expusimos en el citado artículo, y cuales son, en primer lugar la alternativa vinculación del motivo con el mito del repoblamiento del mundo después de una catástrofe, o bien con el mito del origen de un clan; luego la condición de "ave" o de "perro(a)" del animal que se transforma en la misteriosa ama de casa, y, finalmente, el carácter singular o dual de esta última entidad.

\subsection{La vinculación del motivo con el mito del repoblamiento del mundo después de una catástrofe o con el mito del origen de un clan}

Tal como se aprecia, la ya citada versión kaliña representa uno de los casos en que el motivo de "la misteriosa ama de casa" se vincula con el mito del repoblamiento del mundo después de una catástrofe, en este caso la Gran Inundación. A su vez, la acotación de Magaña en torno a que "El mito (...) [arawak] narra la misma historia que los mitos kaliña sobre el origen de arawak", conduce a considerar que la misma vinculación se da en el texto arahuaco.

En este sentido, no obstante, la mención final del texto arahuaco en relación a que “(...) la gente del clan Perro o Ibeswanano descienden de esta unión", podría servir de base para sostener que en este caso el motivo de "la misteriosa ama de casa" se vincula también con el mito del origen de un clan.

$\mathrm{Al}$ rechazar esta doble vinculación, nuestro criterio se fundamenta en el hecho de que la referencia al origen del clan Perro en la versión arahuaca está contextualmente subordinada al mito del repoblamiento del mundo.

En apoyo a esta consideración, cabe hacer notar que son frecuentes las versiones en las que el mito del repoblamiento del mundo manifiesta un marcado etnocentrismo en cuanto a referir que tal repoblamiento se inicia con el pueblo -y a menudo en conjunto con los pueblos vecinos- en cuya tradición se encuentra el mito. Precisamente, la versión kaliña, recién citada, ofrece un claro ejemplo de esta tendencia.

Finalmente, y siempre en apoyo de nuestra posición, debemos precisar que en los casos de las versiones bribri y bororas que hemos expuesto como vinculadas con el mito del origen de un clan (véase Mapa 1), no existe en ellas ninguna referencia a una catástrofe, tal como ocurre en la versión arahuaca.

Sobre esta base, la vinculación con el mito del repoblamiento del mundo que reflejan estas dos versiones, nos lleva a la necesidad de replantear la distribución geográfica expuesta en el Mapa 1, incorporando en él las versiones kaliña (t) y arahuaca, caso este último en el que emplearemos " $m$ ", dado que en nuestro anterior artículo incluímos representada por " $m$ " la versión citada por Hartley B. Alexander, y de la cual este autor no precisaba si su procedencia era arahuaca o caribe. El resultado es así el Mapa 4. 


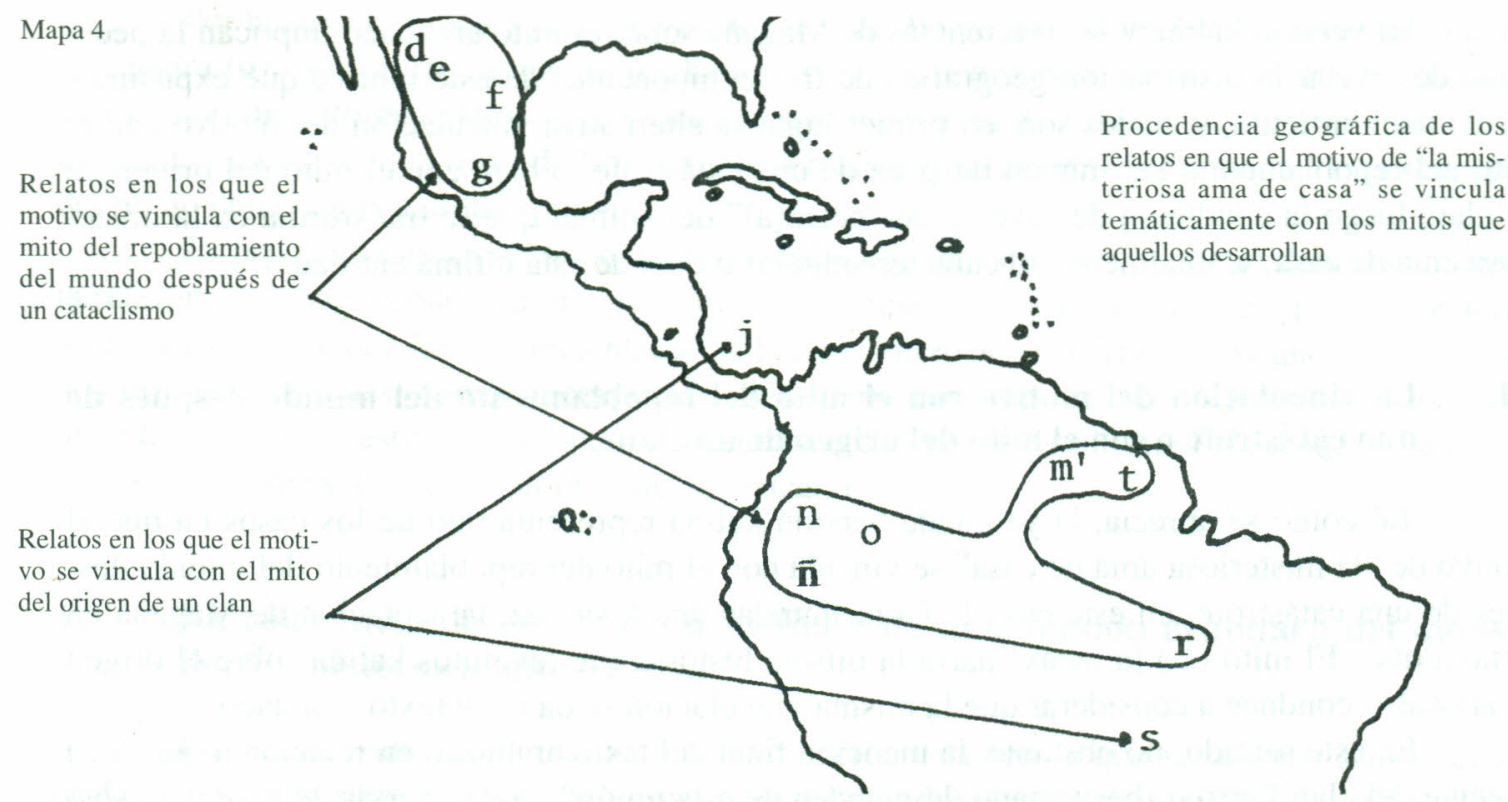

\subsection{Aves o perros(as) como las especies animales que se transforman en "la misteriosa ama de casa"}

En el Mapa 2 se muestra la clara distribución geográfica en lo que respecta a este componente del motivo. Así, el perro o la perra constituyen la especie que da origen a "la misteriosa ama de casa" en las versiones mesoamericanas, en el relato recogido por Taylor en la Isla Dominica (i) y en el texto arahuaco o caribe (m), en tanto que son aves las que desempeñan esta función en las versiones bribri (j), cabécar (k) y maina (n), en el Area Intermedia; en las versiones jívara (o), shikrin (p) y apinayé (q), en el Area Amazónica, y en los relatos karajá (r) y bororas (s), correspondientes al Área del Este del Brasil.

Es precisamente en relación con este componente del motivo donde las versiones kaliña y arahuaca plantean en su desarrollo el elemento más interesante, dado que en ambas especies que dan origen a la misteriosa ama de casa son conjuntamente "un guacamayo y un perro". A esto cabe añadir que en lo que respecta al primero, las dos versiones se inscriben en la tradición en la que con excepción de los relatos shikrin y bororos, las especies que desempeñan este rol son siempre psitácidas, a saber loros, pericos y guacamayos, caso este último de la versión cañarí, muy distante de la región caribe de donde proceden los relatos kaliña y arahuaco, en las que figura esta especie.

La conjunción del ave y el perro como las figuras que dan origen a la misteriosa ama de casa, impone la redistribución geográfica de este componente del motivo, tal como se muestra en el Mapa 5. 


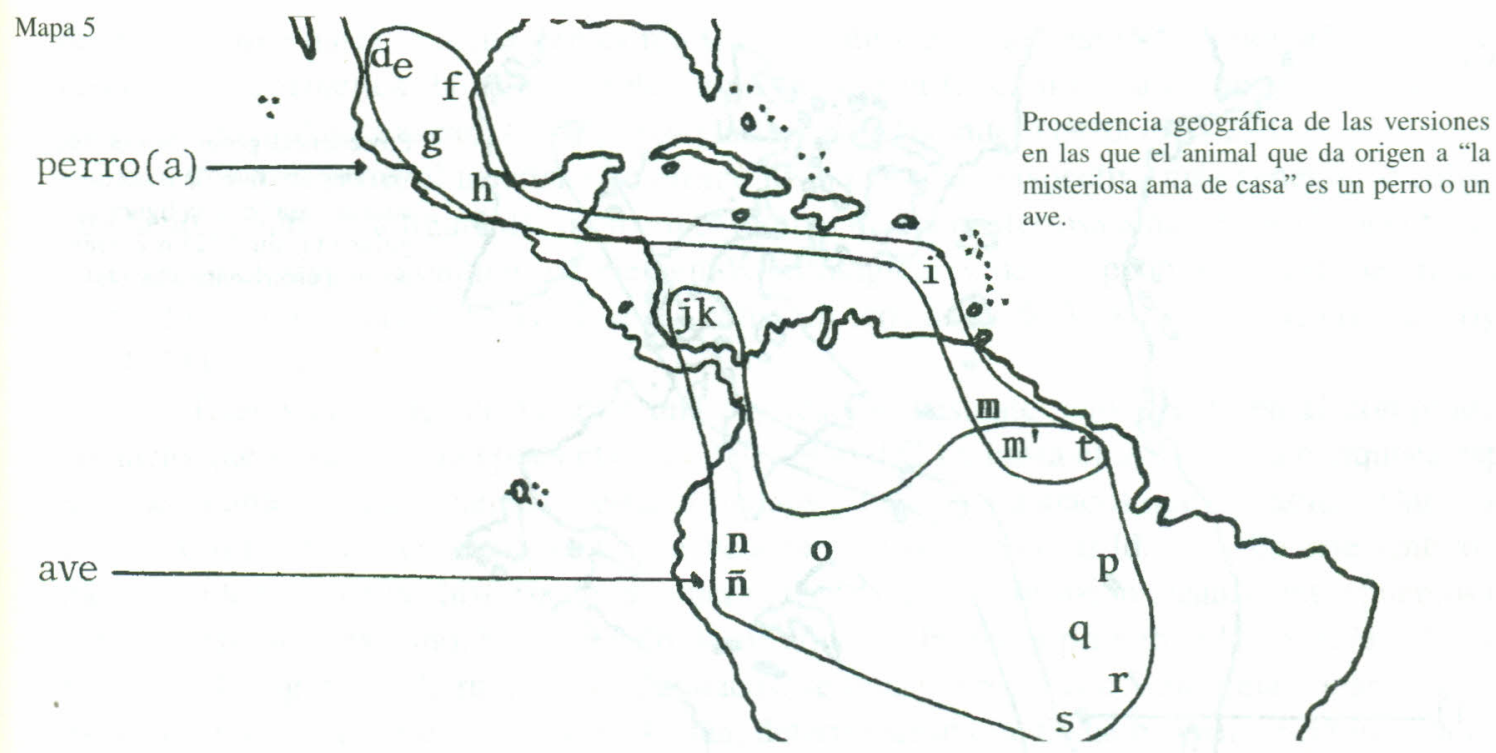

\subsection{El carácter singular, dual o de cuatro entidades correspondientes a la figura de "la misteriosa ama de casa"}

En lo que respecta a este componente del motivo, el Mapa 3 también ilustra una distribución bastante clara. Con excepción de la versión cuna en la que son cuatro las entidades que - desempeñan el rol de "la misteriosa ama de casa", las versiones de la América del Norte (esquimal de Groenlandia (a), esquimal del Labrador (b) y cree (c)), de Mesoamérica (huichol (d), tepecana $(\mathbf{e})$, totonaca $(\mathbf{f})$, tlapaneca $(\mathbf{g})$ y popoluca $(\mathbf{h})$ ), del Area Intermedia (bribri (j) y cabécar (k)), y del Área Caribe (Isla Dominica (i) y arahuaca o caribe (m)) desarrollan el motivo con una figura singular, en tanto que en Sudamérica, en las versiones cañarí (n), maina ( $(\tilde{\mathbf{n}})$, jívara (o), shikrin (p), apinayé (q), karajá (r) y borodas (s) son invariablemente dos las aves que se transforman en "la misteriosa ama de casa".

En este sentido, las versiones kaliña (t) y arahuaca (m'), al hacer figurar en esta función a un guacamayo y a un perro, se inscriben en el paradigma sudamericano, determinando con ello la necesidad de replantear la distribución geográfica expuesta en el Mapa 3, tal como a continuación se expone en el Mapa 6. 


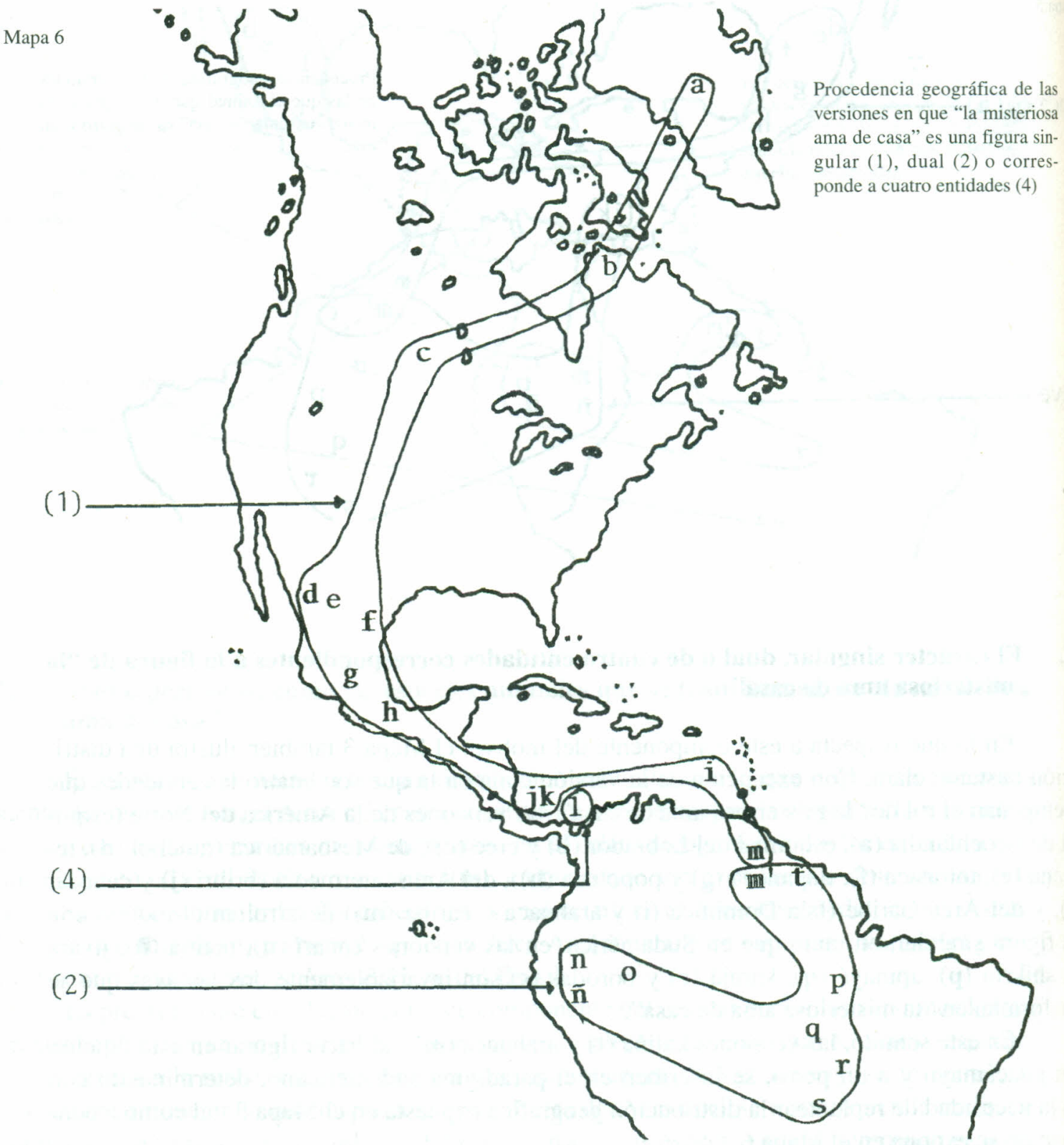

1.4. Alcances sobre las nuevas distribuciones geográficas de los componentes del motivo planteadas por las versiones kaliña y arahuaca

Sin lugar a dudas, el elemento que motiva la redistribución geográfica de los componentes de la "historia de la misteriosa ama de casa" es, en las versiones kaliña y arahuaca, la aparición conjunta del guacamayo y el perro como las especies animales que por transformación dan origen a la figura femenina, lo cual constituye un caso excepcional entre las versiones 
del motivo que hasta la fecha hemos registrado. Aún más, cabe aquí hacer notar que en lo que respecta a Sudamérica, la aparición de un perro en esta función se da en un relato también de procedencia arahuaca o caribe citado por Hartley B. Alexander (1920/1964:274).

Por otra parte, al insertar este último hecho en una perspectiva más general, se constata que la aparición de la figura del perro en el motivo de "la misteriosa ama de casa" constituye un caso más del amplio conjunto de elementos mitológicos y de los pueblos de estirpe arahuaca asentados tanto en las Antillas Mayores como en territorios de Venezuela (Cfr. García Goyco 1984: 111 y ss.)

Tales similitudes encuentran una explicación bastante convincente en el comprobado contacto que a partir de la época clásica ( 250 a 950 d.C.) y hasta el inicio de la conquista española se estableció entre pueblos mesoamericanos y nativos arahuacos que se habían establecido en las Antillas Mayores provenientes de Venezuela (García Goyco Id.: 33). En este sentido, es dable plantẹarse que la "historia de la mujer perro", que tanta difusión alcanzó entre pueblos del actual territorio mexicano, haya viajado desde aquellas latitudes primero a las Antillas Mayores y desde allí, siguiendo la ruta de los arahuacos, se transportara hasta Venezuela, lugar donde las estrechas relaciones entre éstos y los kaliña, determinaron que dicha historia se difundiera también entre los nativos de este último pueblo asentados en Guyana.

\section{Las posibles huellas del motivo en un texto nivaklé}

En el marco de nuestras investigaciones sobre "la misteriosa ama de casa", el límite meridional de la difusión geográfica de este motivo es el que corresponde a sus versiones en la tradición oral de los bororos, en el Área del Este del Brasil.

No obstante, en el Área del Chaco, concretamente en el extremo sudoeste de Paraguay, próximo a la frontera con Argentina, un texto nivaklé, recogido por Celia Mashnshnek, presenta en su desarrollo varios elementos que en su conjunto se corresponden con los componentes del motivo de "la misteriosa ama de casa".

A continuación, ofrecemos nuestra traducción de los pasajes pertinentes de este texto nivaklé, editado por Wilbert y Simoneau (1987: 86-87):

(...) Comenzó a llover copiosamente; llovió toda la noche y a las cuatro de la mañana todo estaba inundado. Todos los niños se habían ahogado, y los mayores se habían subido a lo más alto de sus casas. Los caballos y las cabras estaban atascados en el barro. Entonces las casas se derrumbaron y se hundieron, y el agua las cubrió. Toda la gente se ahogó: todos perecieron.

Sin embargo, un hombre que había estado corriendo toda la noche, llegó a un sitio donde había mucha arena. Sólo una persona había sobrevivido. Había muchos ríos y mucha agua y muchos animales, pero sólo él había sobrevivido. Entonces él se preguntó: "¿Qué voy a hacer yo solo aquí"”. El tenía un arco y flecha, así que salió a cazar y le disparó a un venado. Se sentó y se lo comió. Entonces salió a buscar miel y cuando encontró algo, también se la comió él solo. El se dijo: "Si tan solo el loro fuera una mujer. Si lo fuera, ella podría cocinar y comeríamos juntos". El loro oía y escuchaba lo que él estaba diciendo. Cuando 
el hombre regresó de cazar cerca del mediodía, había una mujer, el loro, parada allí. El hombre miró a su alrededor y preguntó: “¿De dónde vino esta mujer? La lluvia acabó con toda la gente”. El loro era una bella mujer, y él le preguntó: “¿De dónde vienes?". "Yo he estado aquí todo el tiempo", respondió la mujer. "Yo estaba mirando desde allí arriba, ¿no lo recuerdas? Tú dijiste que querías que yo fuera una mujer y que yo podría cocinar y comer contigo. Así lo dijiste". "Oh, pero tú no puedes ser el loro", exclamó el hombre, a lo cual ella contestó: "Sí, lo soy”. Y así, al parecer, ella se casó con él y se embarazó, y tuvo un niño. Cuando el niño creció, ella se volvió a embarazar y tuvo otro. Entonces el hombre tuvo a su mujercita y dos hijos. Aparentemente, nosotros descendemos de ellos. El loro era un chorote, no un nivaklé. Por eso nosotros les decimos Ekluéh a los chorotes. Llamamos a las mujeres Ekluenchéh, y a los hombres, Ekluenúk.

En este texto concurren, a no dudarlo, varios de los componentes del motivo de "la misteriosa ama de casa". De estos componentes cabe citar el diluvio, con la consiguiente desaparición de toda la gente; la figura del único humano sobreviviente, y la presencia del loro -una especie psitácida, de acuerdo con el paradigma sudamericano- que se transforma en mujer y que se une al hombre para repoblar el mundo, dando así origen a los chorotes y a los nivaklés.

No obstante, a pesar de la concurrencia de estos elementos, el relato dista de constituir una versión de "la misteriosa ama de casa", por cuanto en él no se desarrolla el esquema básico del motivo, a saber: el alimento preparado misteriosamente durante varios días, el descubrimiento que el hombre hace de la mujer cuando ésta realiza las labores de ama de casa, y, en este caso, la quema de las plumas, lo cual le impide a aquella retomar su forma animal y la determina a que continúe en el hogar del hombre como su esposa.

Como dato ilustrativo que estimamos pertinente, conviene señalar que de entre sesenta y dos relatos correspondientes al mito del diluvio y procedentes de distintos pueblos del Área del Chaco que hasta la fecha hemos registrado ${ }^{3}$, es éste el único en el que concurren en su conjunto los elementos arriba señalados. Complementando esta acotación, debemos precisar que tampoco hemos encontrado estos elementos en versiones del mito del diluvio o de la gran inundación en pueblos aún más meridionales correspondientes a las áreas Sudandina, Pampeana y Fueguina.

Estos antecedentes, que obviamente corresponden al estado actual de nuestras investigaciones, conducen a plantear la hipótesis de que de existir - tal como creemos que la hay- una relación entre el texto nivaklé y el motivo de "la misteriosa ama de casa", ésta sería el resultado de un desplazamiento de este último desde el Área peruana o, menos probablemente, desde el Área del Este del Brasil, hasta la periferia sudoeste del Área del Chaco, región donde se asientan los nivaklés.

Al margen de este planteamiento, y ya en el terreno especulativo, surge la interrogante en torno a si la elisión del motivo en el texto nivaklé haya tenido su origen en el desgaste narrativo experimentado por el motivo en su itinerario hacia el sur, o bien si tal omisión tuviera lugar en el propio pueblo nivaklé, cuya cultura, al incorporar un relato referente al mito del diluvio desechara de él un episodio absolutamente ajeno tanto a su propia tradición oral, como a la tradición oral de los pueblos vecinos. 


\section{Notas}

1. Con el propósito de contextualizar los contenidos del presente artículo, cabe recordar que Stith Thompson da en su Motif-Index la siguiente descripción de este motivo: Un hombre encuentra su casa puesta misteriosamente en orden. Descubre que la autora del hecho es una muchacha (frecuentemente, un animal transformado en muchacha).

En el marco de este esquema básico, las versiones indoamericanas del motivo incluyen la referencia a los alimentos que a diario el hombre encuentra preparados por "la misteriosa ama de casa".

2. En este Mapa, hemos omitido -en razón de su no pertinencia para los contenidos del presente artículo- las versiones esquimales en las cuales la especie animal es un zorro.

3. Debemos al respecto señalar que en lo referente a mitos del diluvio originados en el Área del Chaco, nuestro corpus comprende textos de los pueblos ayoreo, chamacoco, chané, chiriguano, chorote, mataco, mocoví, nivaklé, pilagá y toba. No hemos registrado relatos relacionados con el mito del diluvio entre los makka, en tanto que entre los caduveo, la temática cataclismológica parece estar ausente de su tradición oral. Ya en un plano general -y no restringido al mito del diluvio- debemos señalar que la lectura de una cantidad cercana a los dos mil textos de la tradición oral de los pueblos del Chaco, no nos ha proporcionado pistas o evidencias, con la excepción de este relato nivaklé, de la existencia del motivo de "la misteriosa ama de casa" en esta Área.

\section{Bibliografía}

Alexander, Hartley Burr. 1920. Latín America. Vol. XI de The Mythology of All Races. Louis H. Gray Ed. New York: Cooper Square Publishers, 1964.

García Goyco, Osvaldo. 1984. Influencias Mayas y Aztecas en los Taínos de las Antillas Mayores. San Juan, Puerto Rico: Ediciones Xibalbay.

Klein, Harriet E. Manelis y Louisa R. Stark. 1983. "Las lenguas indígenas del Chaco Paraguayo". En: Bernard Pottier, América Latina en sus Lenguas Indigenas, 157-80. Caracas: UNESCO y Monte Avila Editores.

Magaña, Edmundo. 1992. "Representaciones inter-étnicas y el sistema regional: el caso kaliñaarawak de las Guayanas". The Journal of Intercultural Studies (The Intercultural Research Institute. Kansai Gaidai University Publication). 19, 62-70.

Margery Peña, Enrique. 1995. "Sobre el desarrollo y la distribución geográfica del motivo de "la misteriosa ama de casa" (N 831.1) en la tradición oral indoamericana". Revista de Filología y Lingüística de la Universidad de Costa Rica. 21(2):107-30.

Wilbert, Johannes and Karin Simoneau Eds. 1987. Folk Literature of the Nivaklé Indians. Los Angeles: UCLA Latin Américan Center Publications. 
